\title{
From (Apparently) Feeling to Being Grateful
}

\author{
David Carr ${ }^{1}$
}

Published online: 24 April 2020

(C) The Author(s) 2020

\section{The Presumed Emotion of Gratitude}

Gratitude is a very familiar human sentiment and latter-day philosophers and psychologists - in an extensive modern literature on the topic ${ }^{1}$ - have largely considered it to be a distinct kind of emotion. All the same, the present paper is concerned to show that while gratitude undoubtedly has significant affective or emotional dimensions and implications, any claim that it is in and of itself a distinct kind of emotion needs questioning in the light of certain problematic inferences into which such a claim may seem to lead us. In this connection, the main focus of following discussion will be upon what is arguably the more primary or basic 'prepositional' form of gratitude (A is grateful to B for $\mathrm{x}$ ), rather than on so-called 'propositional' gratitude (A is grateful or thankful that $\mathrm{p}$ ).

First, suppose that Susan is terrified by the sight of what she takes to be the ghost of her dear dead uncle. Of course, she is mistaken in taking what she sees to be uncle's apparition - which is merely a trick of the light. We may therefore say that she was mistaken in what she believed on this occasion and that her fear (assuming it was based only on optical illusion) was quite unfounded. We might also say that

\footnotetext{
1 See, for example, Claudia Card, "Gratitude and Obligation," American Philosophical Quarterly, 25 [1988]:115-127; Terence McConnell, Gratitude (Philadelphia: Temple University Press, 1993); Patrick Fitzgerald, "Gratitude and Justice," Ethics, 109 [1998]: 119-153; Robert A. Emmons and Michael E. McCullough "Counting Blessings versus Burdens: An Experimental Investigation of Gratitude and Subjective Wellbeing in Daily Life," Journal of Personality and Social Psychology, 84 [2003]: 377-389; Robert A. Emmons and Michael E. McCullough (eds.), The Psychology of Gratitude (Oxford: Oxford University Press, 2004); David Carr, "Varieties of Gratitude," Journal of Value Inquiry, 47 [2013]: 17-28; Liz Gulliford, Blaire Morgan and Kristjan Kristjánsson, "Recent Work on the Concept of Gratitude in Philosophy and Psychology," The Journal of Value Inquiry, 47 [2013]: 285-317; Philip C. Watkins, Gratitude and the Good Life: Towards a Psychology of Appreciation (Dordrecht: Springer, 2014); David Carr, (ed.), Perspectives on Gratitude: An Interdisciplinary Approach (London and New York: Routledge, 2016; Jonathan R. H. Tudge and Lia B. L. Freitas (eds.), Developing Gratitude in Children and Adolescents, Cambridge: Cambridge University Press, 2018); Robert C. Roberts and Daniel Telech (eds.), The Moral Psychology of Gratitude (London and New York: Rowman and Littlefield, 2019).
}

David Carr

dcarr@staffmail.ed.ac.uk

1 Moray House School of Education, University of Edinburgh, Holyrood Road,

Edinburgh EH8 8AQ, UK 
she was wrong to experience fear or that she ought not to have felt it. That said, we need not in the least doubt that what she did experience on this occasion was the feeling or (perhaps) emotion of fear: the fear was a very real response to or consequence of what she imagined she saw. To be sure, fear is a fairly basic species of affect - whereby sentient creatures other than humans are afflicted - and there are fairly simple and straightforward ways of establishing its occurrence in the case of both human agents and other sentient creatures. In the spirit of Wittgenstein ${ }^{2}$ we might say that - at least in our own case - we need not seek knowledge of either pain or fear, since we are liable to immediate experiential impact by such states leaving little room for doubt that we are in fact hurting or afraid. So while fear may also sometimes be an intentional state - in the philosopher's sense of requiring belief or some other kind of cognition or rational appraisal - it may yet occur, even in human agents, in the absence of such cognition: Susan might just as well have been terrified by a sudden visual effect that she did not at the time take to be anything in particular.

What, then, of emotional states of greater intentional content and direction wherein some level of belief, cognition or appreciation is more clearly involved or interwoven with affect? Suppose, for example, that Susan is jealous of her sister Caroline because she believes that her alive and kicking uncle - with whom she is mildly infatuated - favours her sibling over herself. In actual fact, Susan's jealousy - as is no doubt common enough in cases of this emotion - is just another product of her own over-heated fancy: while her uncle actually goes out of his way to treat both of his nieces with scrupulous and even-handed fairness and equality of regard, he is in truth actually more sentimentally attached to Susan than to Caroline. So, once more, we need to say that Susan is or was mistaken in what she believed about her uncle and that her jealousy on this or other occasions was quite misplaced. In this case, we might also say - perhaps with greater normative force - that she was wrong to feel jealousy or that she (morally) ought not to have entertained it - since her uncle might well feel hurt or slighted if he knew. As in the case of her previous fear, however, we need not seriously doubt that what she experienced at the time - well before she came to realise that her emotion was unfounded - was a genuine bout or episode of the feeling or emotion of jealousy: such jealousy was a real enough response to or consequence of what she perceived or imagined to be the case about her uncle's view of her vis a vis her sister.

However, suppose now that Susan's dearly beloved uncle has just died and that she is assured, on the authority or testimony of a close friend of his, that she has been generously provided for in his will. In confident anticipation of such benefit, Susan is therefore drawn to gratitude towards her uncle. Sadly, however, her hopes are dashed since her uncle has left his entire estate to the hitherto unsuspected illegitimate offspring of a former pre-marital affair, regarding which - while no doubt also well-disposed to his niece - he had long felt profound guilt. In consequence - while not unsympathetic to his final testament - Susan is understandably disappointed and certainly no longer sees or feels any reason to be grateful to her uncle for a benefit that she did not in the event receive. So, once more, we seem required

\footnotetext{
${ }^{2}$ Ludwig Wittgenstein, Philosophical Investigations (Oxford: Blackwell, 1953).
} 
to say that Susan is or was mistaken regarding what she took to be her uncle's beneficence towards her and that her anticipatory gratitude was simply misplaced. As in the case of misdirected jealousy, we might also say that since any gratitude towards which she was inclined was unwarranted, she therefore ought not to have felt it and that the eventual lack of benefit entirely removes any requirement for further grateful or associated sentiments. All the same, as in the cases of her previously noted fear and jealousy, should we not also say that before she learned that no avuncular legacy was to come her way, she was - in virtue of the feeling or affect attendant upon her previous disposition to gratitude - nevertheless actually grateful at that time? This, however, does not sound quite right.

\section{The Affective Complexity of Gratitude}

To begin with, it may be useful to set out the best case for supposing that the apparently grateful feelings that Susan experienced in advance of learning that no benefit was coming her way might nevertheless count as actual gratitude. In brief, the main argument would appear to run as follows: (i) gratitude - along with fear and jealousy - entails or just is a distinct type of feeling or (more precisely) an emotion; (ii) insofar as Susan's former feelings were apparently governed, shaped or directed in accordance with anticipation of her uncle's endowment, this would seem tantamount to an emotion of gratitude; (iii) ergo, by virtue of the occurrence of such (allegedly) grateful emotion, Susan must nevertheless have been truly grateful at the time of her mistaken expectation - much as she might have been mistakenly but no less actually jealous. To be sure, some such conclusion seems amply supported by an almost unanimous philosophical (as well as social scientific) consensus to the effect that gratitude does have such a distinct emotional nature or core. Indeed, perhaps especially among those strongly inclined to regard gratitude as a moral quality or virtue, ${ }^{3}$ its affective or emotional character would appear to be quite crucial to such virtuous status: what precisely distinguishes virtuous gratitude from common - and often near meaningless - utterances of thanks as mere social courtesy is the presence of sincere and heartfelt sentiments or feelings towards benefactors for gifts or favours. Of course, such feelings need to be appropriately guided by a clear grasp of the logical grammar of the concept in this or that particular case; but in the absence of appropriate feeling or affect, such understanding must also fall short of genuine gratitude. In this light, it seems useful to proceed with some exploration of the affective dimensions of gratitude: precisely, of its status or prospects as a distinct emotion.

While recent philosophical attention to emotion is extensive and complex - if not prey to some rather heavy weather - there would appear to be a large consensus to the effect that emotions are rich composites of affect and cognition. Hence,

\footnotetext{
3 See, for example, Christopher H. Wellman, "Gratitude as a Virtue," Pacific Philosophical Quarterly, 80 [1999] 284-300; Robert C. Roberts. "The Blessings of Gratitude: A Conceptual Analysis," in The Psychology of Gratitude, edited by R. A. Emmons and M. E. McCullough (Oxford: Oxford University Press, 2004) 58-78; Kristjan Kristjánsson, Virtuous Emotions (Oxford: Oxford University Press, 2018).
} 
despite some past tendency to reduce emotions to mere feelings and some more recent inclination to construe them as less affective modes of cognitive appreciation or appraisal, they are perhaps best understood as states of rationalised or cognised affect or feeling. ${ }^{4}$ This would seem broadly consistent with Aristotle's distinction in Nicomachean Ethics of the emotions of moral virtue from the more primal affect of natural virtue, and - among more recent accounts - Roberts' characterization of emotions as 'concern-based construals' ${ }^{5}$ may well be a modern version of this notion. At all events, it seems wise to distinguish between fear as a matter of brute feeling - of the kind that sentient but non-human creatures undoubtedly experience - and the informed emotion of fear that only rational human (or other) agents might entertain. Hence, while both human agents and their close evolutionary relatives may equally fear the crash of thunder and lightning, it is hardly open to the latter to be afraid of their financial ruin following collapse of the stock market. Susan or her dog may be equally terrified by the sudden weird glow in the room, but only Susan can be afraid that her uncle has returned to haunt her.

This said, while Susan's fear of her uncle's ghost is doubtless a more cognitively shaped affective episode, one may yet have reservations about quite regarding this as an emotion. Unlike affectively reactive episodes of fear or rage, emotions seem to be psychologically or morally complex states or attitudes of appreciation of the world, of ourselves or our relations with others, that dispose agents to correspondingly appropriate patterns of purposeful conduct. In this light, emotions might be taken to include such states, sentiments or attitudes as love, hate, pride, resentment, relief, compassion, jealousy, envy, pity, generosity - or, as seems often supposed, gratitude. To be sure, as already observed from our second narrative, Susan's jealousy of her sister as an imagined rival to her uncle's affections would seem to qualify as a cognitively and affectively complex state or attitude of this general kind. Still, it also appears that the feeling underpinning such emotions as love, hate, pride, envy, compassion and jealousy is correspondingly richer or more complex than that of such affective episodes as fear or rage. For example, in the case of Susan's jealousy of sister Caroline as an imagined rival for her uncle's affections, such jealousy may well combine hatred or resentment of her sister with fear of loss of her uncle's affections.

In short, the emotion of jealousy would not seem tied to any one basic feeling but to be a composite or cocktail of rather different ones. That said, what unites such different negative feelings of insecurity and resentment under the single heading of jealousy is a general sense of unwelcome abandonment and/or loss. It would also appear that jealousy, like fear and rage, is a fairly visceral mode of affect, which - while the basic feelings that it arouses may well be present in other emotions - is nevertheless fairly experientially unique. Indeed, it may be that agents sometimes come to recognise that they are jealous only via the sudden onset of a peculiar mix of insecurity about A, and resentment of B who is thought to be now favoured by A,

\footnotetext{
${ }^{4}$ For a recent account that strongly emphasises the role of affect and its interplay with cognition in emotion, see David Pugmire, Rediscovering Emotion (Edinburgh: Edinburgh University Press, 1998).

5 See Robert C. Roberts, "What an Emotion Is: A Sketch," The Philosophical Review, 97 [1988]: 183209.
} 
that jealousy entails. It might also be held, albeit more controversially, that creatures incapable of the intentionality or rational cognition of human agents, such as pet dogs or cats, can experience jealousy - though there is an obvious danger of mistaking kinds of attention-seeking animal behaviour for the more cognitive states attributable to an Othello or other fictional or real human agents. Be all this as it may, given the basic logical grammar and conditions of jealousy, the diverse forms of affect that it is liable to entrain make fairly easy bedfellows: knowing what jealousy is, it is not hard to see why I would feel abandonment or loss at A's sudden attention to B together with some hostility or resentment towards B.

But what should we now say of Susan's purported grateful sentiment towards her uncle in light of her false expectation of his bequest? How, indeed, might we go about making sense of gratitude as an emotion in the manner of fear or jealousy? To begin with, it seems clear that the affective dimensions or entanglements of gratitude are - like those of jealousy - more complex and diverse than those of fear or rage. On the other hand, since the actions or events for which agents may be expected to be grateful are by definition benefits, the feelings and responses of such agents might also be construed as generally positive or pleasurable - as those of the jealous are largely negative and unpleasant. Why, in short, would or should one be grateful to others if not in recognition or appreciation that something has been given or done to one that is conducive to pleasure or happiness? In this spirit, we may suppose Susan to have been happy in anticipation of her uncle's beneficence, and to have been disappointed and saddened when her expectations were not met. Still, a little further reflection - not least in the light of past and recent attention to tensions between the voluntary and obligatory aspects of gratitude - suffices to show that this is a much too simple picture of the nature and involvement of affect in many cases of genuine gratitude. Thus, generally, it may be too easily assumed that being put in a position whereby gratitude appears required is something that agents are bound to find congenial: in this regard, indeed, Aristotle ${ }^{6}$ notoriously held that his agents of great-soul should avoid such predicament, precisely insofar as it placed them under compromising and/or demeaning obligation to others.

To be sure, Aristotle's point seems to have been that since gratitude is an inherently subservient state, it is a degrading and thereby undesirable condition to be generally avoided. Still, one may also hold that gratitude is a perfectly good or desirable response while nevertheless feeling compromised by or uncomfortable with it. Hence, in addition to those who actually resent any obligation to be grateful on a given occasion - which, to be sure, is not inevitably inconsistent or incompatible with some appreciation of benefit or benefactors - there may be those who, while genuinely grateful to such benefactors, experience considerable discomfort or embarrassment regarding benefits that they deem personally undeserved. Again, one might be genuinely grateful to some benefactor for a gift or favour to which one attaches little or no value and that one only regards as a pathetic or clumsy attempt to express love or attachment: one warms to the benefactor for the effort and sentiment

\footnotetext{
6 Aristotle, Nicomachean Ethics, in The Basic Works of Aristotle, edited by R. McKeon (New York: Random House, 1941) 1124b 9-11, p. 993.
} 
invested, but derives negligible satisfaction from it (and it may be that many Christmas presents from well-meaning relatives fall into this category). In short, while there is a clear affective dimension and direction to such states or attitudes as jealousy, envy or pride - by virtue of which they might be considered separately identifiable emotions - the feeling or affect associated with gratitude, especially given the psychologically and socially complex range of circumstances in which occasions for gratitude are liable to arise, may seem too diverse or variable to warrant identification of any separate or distinct emotion of gratitude.

True, the positive attitudes and/or feelings most commonly found in the presence of gratitude are probably appreciation of the benefit and kindliness or positive regard towards benefactors - and this may well be the key source of confusion with respect to this issue. But, of course, these qualities are neither sufficient nor necessary for gratitude - for there may be either appreciation or kindliness without gratitude or gratitude in the absence of (either) appreciation or positive regard. In any case, since appreciation seems to be a kind of composite of understanding and valuing - either of which may be quite dispassionate - its affective involvement and/or emotional credentials seem doubtful. On the other hand, while kindliness, other-regard, love, pride, pleasure, happiness, anxiety, resentment, embarrassment, compassion, pity or condescension may variously accompany genuine gratitude on this or that occasion, it would seem mistaken to identify this attitude or disposition with any of these sentiments as such, or even - as with jealousy - with some determinate combination or cocktail of such states. So while in the case of Susan's albeit unfounded jealousy of her uncle, it is possible to appreciate what it might at the time have felt like for her to experience this emotion - precisely, for her to have been specifically jealous - it is less easy to imagine what it might have felt like for her to have had an albeit mistaken emotion of gratitude to her uncle. The best that we might here say is that Susan entertained a thought or belief that she was grateful to her uncle - a belief that eventually turned out to be unwarranted. In that case, unlike the cases where she was mistakenly but nevertheless actually fearful or jealous, such uncertainty about any distinctive emotion of gratitude does little to support any conclusion to the effect that she actually was grateful. Moreover, such suspicion seems strongly reinforced by other conceptual or grammatical features of gratitude that also compellingly point to the conclusion that she could not have been grateful in her mistaken expectation of benefit.

\section{Gratitude, Relation and Benefit}

So far, we have argued that Susan could not have been actually grateful to her uncle by virtue of having experienced an albeit mistaken emotion of gratitude, insofar as it seems hard to pin down any such distinctive emotion. Contrary to what many contemporary philosophers have argued (or perhaps more commonly assumed), while gratitude clearly has affective dimensions, associations and/or implications - insofar as expressions of thanks might not count as genuine gratitude in the absence of some feeling or other - such affect seems rather too variable or diffuse to determine any unique omnipresent emotion of gratitude as such. Rather, gratitude seems 
to be exhibited in different cocktails of cognition and feeling on different occasions of occurrence. But, in that case, by virtue of what common feature might all such diverse composite states count as tokens of gratitude? Perhaps the clearest common feature, none the worse for being obvious, is that any episode of gratitude would need to entail belief that one has been benefited by another agent in a manner that requires some acknowledgement or appreciation. Just as Susan might have believed that she was heavier than her sister, but later realised that she was mistaken, so she might have entertained a conviction that she was grateful to her uncle before coming to realise that this was unfounded. Still, this would only warrant Susan later saying that she had thought she was grateful to her uncle - before coming to realise that she was not - not that she formerly was grateful to him. For the stronger conclusion, we would have to suppose that being grateful is in and of itself a distinct type of belief, not just a matter of entertaining the potentially right or wrong content of some more basic proposition. In this light, gratitude might possibly be regarded as a kind of self-authenticating belief or attitude - perhaps somewhat in the manner of love.

To be sure, love is often taken to be a genuine emotion; but it has also been customary to distinguish between different kinds of love, ${ }^{7}$ not all of which need be especially passionate, affective or emotional. All the same, agents of this or that sort of love might often be regarded as final authorities on whether or not they do, or are in, love. Of course, this is not to say that people cannot be mistaken about whether or not they are in love - and it seems crucial to the presently proposed analogy with gratitude that this is so. Thus, agents may say that while they had supposed themselves to be passionately in love, they came to realise that what they felt was just a passing infatuation. More to the present point, lovers might be mistaken about the object of their love. To take a slightly far-fetched example, in the recent sci-fi movie $\mathrm{Her},{ }^{8}$ the main character becomes amorously and erotically attached to an artificial intelligence of female persona programmed into or onto his computer. Still, while this movie is concerned to explore the inevitably bizarre consequences of this relationship, it might nevertheless be said that since the target of erotic attachment here is simply not - perhaps any more than any other mechanical device (such as one's electric toothbrush) - an appropriate object of human love, one would have to reject any claim to love of this kind as ultimately misplaced, deluded or false. Be that as it may in this particular case, the key present point is that any genuine love requires an appropriate amorous or erotic object or target - without which, indeed, any claim to have loved may be quite forfeit.

On this view, however, an appropriate object of love seems to be a more important desideratum of this or that claim to have loved, than any feeling or belief that one has or had loved - since there might well be genuine love in the absence of any such belief or affect, as well as other ways of determining that genuine love had occurred. ${ }^{9}$ At all events, what is here crucial is that love would seem to be essentially

\footnotetext{
7 For one notable instance, see C. S. Lewis, The Four Loves (London: Collins, Fount Paperbacks, 1960).

8 Spike Jonze, Her (Motion Picture: Warner Brothers, 2013).

9 One may here recall Wittgenstein's observation that love is not a feeling insofar as it may be put to the test: Ludwig Wittgenstein, Zettel (Oxford: Blackwell 1967) 504.
} 
relational by virtue of being focused or targeted on another appropriate agent or object. While this need not be the case of Susan's fear - since she can still be said to have feared even if her fear was imaginary - it does also seem true of her jealousy, since there would have to have been someone of whom she was jealous in order for her to have been genuinely jealous, whether or not such jealousy was misplaced or irrational. But what here appears true of love and jealousy seems to be even more so of gratitude: just as genuine jealousy or love needs to be or to have been of someone, so gratitude (at least in the present prepositional sense) would need to be or have been directed to someone. And, to be sure, it seems clear enough that Susan's supposed gratitude, no less than her jealousy of her sister, was indeed directed to someone: namely her uncle.

Why, then, can we not now say that Susan's gratitude to her uncle, no less than her jealousy of her sister, was - albeit now appreciated as misplaced - none-theless previously real? Like her jealousy, it was certainly directed towards her uncle and therefore fully relational. However, while gratitude evidently resembles jealousy and love by virtue of its relational status, it seems yet more complex and to require something more for full satisfaction. In general, any relation between those who are jealous and those of whom they are jealous goes in one principal direction: in short, one would not normally expect the latter to be jealous by return of the former. In the case of love, of course, one might expect or hope - if all goes well - that those who love might be loved in return by those whom they love. But this is evidently far from inevitably the case and genuine love is often unrequited. Hence love, no less than jealousy, may also move in only one direction and we would not regard it as fatal to any claim to have loved - even if one no longer does so - that the love was not returned at any time. On the other hand, justified responses or expressions of gratitude - at least of the regular or basic interpersonal variety - need to be not only relational but also dependent upon the agency of others. For genuine gratitude, there needs to be not only someone - a benefactor - to whom thanks are due, but also something in virtue of which that agent counts as a proper target of such thanks: namely, a genuine benefit. In the case of Susan's supposed gratitude to her uncle for the anticipated benefit, however, this condition is evidently unfulfilled: there simply was no benefit, her uncle was never a benefactor and Susan could not therefore have been grateful, however much she may have felt or believed herself to be so at the time.

In this light, the grammar of gratitude seems less like that of love or jealousy and more like that of forgiveness, wherein something quite like an actual benefit also needs to be granted or bestowed to justify any claim to have been genuinely forgiven. Hence, suppose that Susan said or did something unkind to her dearly beloved uncle, but - repentant and anxious to make amends - she is assured by the evidently unruffled response of her uncle and the testimony of a close friend of his that she has actually been forgiven. In her anxiety and need to be forgiven, Susan is all too ready to think herself forgiven and does actually feel or take herself to have been so. Sadly, however, she later learns that her uncle has been deeply wounded by her actions and/ or words, has been quite unable to forgive her and wants nothing more to do with her. Once more, we seem required to say that Susan is or was mistaken in what she took to be her uncle's forgiveness of her and that any previous thoughts or feelings 
that she had been forgiven are quite misplaced. However, as in the cases of her misplaced fear and jealousy - contexts in which we would not be inclined to deny that she was nevertheless fearful or jealous at the time - should we not also be here disposed to say that since she had formerly felt or thought herself to be forgiven, she had been so at the time? Significantly, however, we feel hardly any temptation to say anything of the kind. Regardless of how she may have felt, Susan was at no time forgiven and was merely deluded in supposing herself to have been so.

It also seems clear that the reason why we are not tempted to suppose otherwise is that forgiveness is precisely something that is granted or bestowed by others: it is not (despite the dubious claims of advocates of self-forgiveness) in the gift of the offending agent to secure and so any feelings, thoughts or wishes to be forgiven on the part of the offending agent have simply no bearing on whether forgiveness has actually been granted. But it should be no less clear that gratitude is also an appropriate response only to a good or benefit that has actually been bestowed or granted and is therefore no less inappropriate in the absence of such benefit: this is precisely why Susan should cease to feel or experience it when she discovers that no benefit was actually forthcoming. In that case, what accounts for the greater uncertainty that we may experience about concluding that Susan was not grateful as she felt herself to be when she expected the benefit? Apparently, it can be no more than the thought that her earlier expectation of benefit did appear to be attended by feelings apt for construal as a distinct emotion of gratitude.

Still, while we need not doubt that Susan felt something at the time of her expectation of benefit, this could have been any of a variety of feelings, passions or emotions - such as appreciation, kind regard, love, irritation, resentment, embarrassment, pity, condescension or whatever - none of which may be considered strictly necessary for this or that legitimate expression of gratitude (as, say, hurt and resentment seem to be for jealousy) or to amount to anything worth regarding as a distinct emotion of gratitude. But did we not earlier admit that gratitude is at least liable to be informed by some kind of appreciation or liking for gift or giver? In the first place, however, a beneficiary may well love the gift and hate the giver - or vice versa - and both these mixed emotional states are quite consistent with genuine gratitude to or for something or someone. But, more strongly, there may well be gratitude without much regard for either giver or gift. Thus, infant Susan strongly dislikes her old uncle - who is boring and smells of whisky and tobacco - and is even less impressed by the poetry book he gives her for her birthday. Indeed, like the rest of us she is more than likely fated to a lifetime of disappointing (as well as welcome) gifts from insufferable (as well as admirable) givers. Still, encouraged by her parents to consider her uncle's feelings and the effort to which he has gone on her behalf - as well as to write him a letter of thanks - she comes to appreciate the spirit of kindness and good will in which such gifts are often made and - if all goes well - to learn herself to give and take in just the same spirit (if not indeed, by much the same token, to come to treasure and profit from her uncle's gift of the poetry book).

At all events, like the rest of us, younger or older Susan is no doubt headed for a veritable maelstrom of future feelings of elation, disappointment, joy, resentment, irritation, sympathy, liking and disliking in the course of (despite Aristotle) largely unavoidable entanglement with the all too human business of giving and receiving. 
But coming to engage in this humanly significant practice is not primarily, if at all, a matter of developing, nurturing or honing any of a wide possible range of gratitudeimplicated feelings or emotions, singly or in combination. Rather, it is a matter of learning to respond in kind to the kindness of others - either with the help of or in spite of such wayward affect - and this is more a matter of some (imaginative) comprehension of or insight into the best of human motivational nature, as well as of principled commitment to further promotion of the higher reaches of that nature (including one's own). However, the intense pleasure and joy that such positive reciprocity is able to bring and the hopes and expectations that it also has the power to satisfy are no less clearly dependent upon the actual effects of such human kindness and generosity rather than upon our hopes and dreams of such: precisely, upon actual delivery of the goods. Thus, returning to the Susan of disappointed inheritance, it seems that there can have been little more to her former feeling of gratitude than the pious and misinformed hope of such benefit. Failing actual benefit, however, such pie in the sky hopes are really neither here nor there. Hence, as in the case where Susan mistakenly felt herself to have been forgiven, but she had not been so, it seems no less true that Susan could not have been grateful for a benefit that she never received, quite irrespective of how she may have felt when she thought to receive it. Above all, it seems doubtful whether any of her feelings at this or other times may be taken to comprise a distinct and unique emotion of gratitude, insofar as it seems neither coherent nor helpful to suppose that there is any such article.

Open Access This article is licensed under a Creative Commons Attribution 4.0 International License, which permits use, sharing, adaptation, distribution and reproduction in any medium or format, as long as you give appropriate credit to the original author(s) and the source, provide a link to the Creative Commons licence, and indicate if changes were made. The images or other third party material in this article are included in the article's Creative Commons licence, unless indicated otherwise in a credit line to the material. If material is not included in the article's Creative Commons licence and your intended use is not permitted by statutory regulation or exceeds the permitted use, you will need to obtain permission directly from the copyright holder. To view a copy of this licence, visit http://creativecommons.org/ licenses/by/4.0/.

Publisher's Note Springer Nature remains neutral with regard to jurisdictional claims in published maps and institutional affiliations. 